Etnográfica

Revista do Centro em Rede de Investigação em

Antropologia

vol. $25(2) \mid 2021$

Vol. 25 (2)

\title{
Quem faz gemer a terra? Notas sobre o cotidiano de uma pesquisa de emprego e desemprego
}

Who makes the earth groan? Notes on the day-to-day of an employment and unemployment research

\section{Juliano Florczak Almeida}

\section{(2) OpenEdition}

Journals

Edição electrónica

URL: https://journals.openedition.org/etnografica/9736

DOI: $10.4000 /$ etnografica. 9736

ISSN: 2182-2891

Editora

Centro em Rede de Investigação em Antropologia

Edição impressa

Paginação: 357-377

ISSN: 0873-6561

Refêrencia eletrónica

Juliano Florczak Almeida, «Quem faz gemer a terra? Notas sobre o cotidiano de uma pesquisa de emprego e desemprego », Etnográfica [Online], vol. 25 (2) | 2021, posto online no dia 29 julho 2021, consultado o 19 janeiro 2022. URL: http://journals.openedition.org/etnografica/9736 ; DOI: https:// doi.org/10.4000/etnografica.9736

Etnográfica is licensed under a Creative Commons Attribution-NonCommercial 4.0 International License. 


\section{Quem faz gemer a terra? Notas sobre o cotidiano de uma pesquisa de emprego e desemprego}

\section{Juliano Florczak Almeida}

Este trabalho apresenta uma etnografia de práticas das ciências humanas. Em uma experiência de autoantropologia, o autor busca seguir a trajetória de construção dos dados estatísticos da Pesquisa de Emprego e Desemprego da Região Metropolitana de Porto Alegre (PED-RMPA). Para tanto, utiliza-se de participação observante (pois, além de etnógrafo, é um dos etnografados), registrada em diário de campo, entrevistas com colegas e consulta a documentos que norteiam a pesquisa, especialmente manuais. Esses materiais sugerem que um dado estatístico é um coletivo, capaz de carregar todo um universo. Busca-se, então, refletir sobre a capacidade de agência das coisas que compõem esse universo. E, por fim, sobre a viabilidade de uma experiência de autoantropologia.

PALAVRAS-CHAVE: etnografia, autoantropologia, antropologia da ciência, agência, autoria, PED-RMPA.

Who makes the earth groan? Notes on the day-to-day of an employment and unemployment research - This paper shows an ethnography of human sciences practices. In an autoanthropology experience, the author aims to follow the trajectory of construction of statistical data in the case of Pesquisa de Emprego e Desemprego da Região Metropolitana de Porto Alegre (PED-RMPA). Therefore, the used methodology comprehends the observant participation (because the researcher is both ethnographer and member of the researched group), whose notes were registered in a field diary, interviews with workmates and analyses of PED's documents, especially the manuals. These materials suggest statistical data is a collective that can carry a universe. This paper also reflects on the ability of agency of things that make up this universe. And about the viability of an autoanthropology experience.

KEYWORDS: ethnography, autoanthropology, anthropology of science, agency, authorship, PED-RMPA.

ALMEIDA, Juliano Florczak, (juliano-florczak@hotmail.com) - Instituto de Filosofia e Ciências Humanas, Universidade Federal do Rio Grande do Sul, Brasil. 


\section{INTRODUÇÃO}

Quando junho de 2015 estava começando, nós, trabalhadores da Pesquisa de Emprego e Desemprego (PED) da Região Metropolitana de Porto Alegre (RMPA), ${ }^{1}$ ainda estávamos lidando com o material do mês de maio. ${ }^{2}$ Dentre os questionários que a equipe de crítica precisava examinar, ${ }^{3}$ a situação de um indivíduo me chamou a atenção. ${ }^{4}$

Tratava-se de João, residente em Alvorada (RS). Segundo o questionário, João, homem branco de $4 \mathrm{l}$ anos casado com Maria, trabalhava de segunda a sábado como motorista de ônibus. ${ }^{5}$ Há cinco anos e meio era empregado assalariado com carteira assinada em uma empresa de transporte coletivo. Recebia mensalmente R\$ 1500 pelas 48 horas semanais em que dirigia ônibus pelas ruas de Alvorada.

O questionário da família de João seria apenas mais um dos cerca de 400 que um "crítico" examina por mês. Uma anotação, contudo, apresentada no verso do questionário, pôs em relevo o caso de João. No questionário, João aparecia como um ocupado, mas a entrevistadora, uma das mais experientes da PED-RMPA, escreveu no verso que João perdeu o emprego naquele dia em que o questionário foi aplicado. Não é à toa, pois, que no dia anterior a entrevistadora não havia encontrado ninguém no domicílio, já que visitou a casa no período da tarde, turno em que João e sua esposa costumavam estar trabalhando.

I Gostaria de agradecer aos meus colegas de trabalho, que muito gentilmente aceitaram participar desta experiência etnográfica. Também gostaria de expressar meu agradecimento ao professor Ruben Oliven e aos meus colegas de doutorado pelos interessantíssimos comentários ao meu roteiro etnográfico. Um agradecimento especial para a Luciana Pêss, a minha colega de PED-RMPA que leu a primeira versão do texto e também fez ricos comentários. Devo ainda mencionar os(as) pareceristas anônimos(as) da revista, cujos pareceres permitiram aprimorar a análise e a apresentação dos dados. O título deste artigo é uma homenagem ao livro homônimo de Charles Kiefer.

2 A Pesquisa de Emprego e Desemprego (PED) surgiu na década de 80 em São Paulo. A metodologia da pesquisa foi desenvolvida pelo Departamento Intersindical de Estatística e Estudos Sócio-Econômicos (DIEESE) e a Fundação Sistema Estadual de Análise de Dados (Seade). Durante a década de 90, passou a ser aplicada em outras regiões metropolitanas. Quando da realização da pesquisa, além de São Paulo, também Belo Horizonte, Distrito Federal, Fortaleza, Porto Alegre, Recife e Salvador integram o chamado Sistema PED. Em cada região metropolitana, o DIEESE e o Seade articulam acordos regionais com instituições estaduais. A PED-RMPA é o resultado da parceria dessas duas instituições com a Fundação Gaúcha do Trabalho e Ação Social (FGTAS), a Fundação de Economia e Estatística (FEE) e a Prefeitura Municipal de Porto Alegre. A pesquisa em Porto Alegre foi descontinuada em 2018 depois de quase 30 anos de série histórica.

3 O questionário da PED está intimamente relacionado com a diferença com relação a outras pesquisas sobre desemprego. Como há uma enorme preocupação com a série histórica, o questionário é o mesmo desde seus inícios. O questionário é em papel e, atualmente, está sendo digitalizado.

4 Grupo do qual faço parte, a equipe de crítica é responsável pela avaliação metodológica de cada questionário. Nos próximos tópicos do texto, as atividades desenvolvidas por cada equipe, bem como os pormenores da pesquisa, ficarão mais claros.

5 Os nomes foram alterados porque a PED compromete-se com o sigilo das informações. Seguindo o mesmo padrão, os meus interlocutores também tiveram seus nomes alterados. 
Imediatamente me lembrei da primeira vez em que tive que analisar um caso similar ao de João. À época, fiz uma "crítica", ocorrência apontando possível incoerência ou má apresentação das informações, solicitando a incorporação da observação de que o entrevistado havia sido demitido. Como minha solicitação não foi atendida, fui conversar com a supervisora, colega minha que tem um contato mais imediato com os entrevistadores, como se verá adiante. $\mathrm{Na}$ sala da supervisão, estava um entrevistador que, ao contrário de mim, novato na pesquisa, há anos aplicava questionários da PED. Quando relatei o caso, o entrevistador, mesmo deixando transparecer certa empatia para com minha posição, foi enfático: "Não tem o que fazer! É isso aí mesmo."

De fato, como a questão 17, que é classificatória e separa ocupados de inativos, pergunta se o indivíduo desenvolveu algum trabalho nos últimos sete dias, pessoas que saíram do emprego há um, dois, até seis dias serão tornadas ocupadas. João é um ocupado na base de dados da PED mesmo tendo perdido o emprego.

Situações como essa eram bastante incômodas para mim. Por um lado - o meu "lado cientista" -, havia a convicção de que uma pesquisa científica precisa estar calcada na realidade. E eu sabia que a vida de João não era mais a de um ocupado. Por outro lado - certo "lado ativista político" -, afetava-me profundamente a ideia de que a realidade de João - que eu, secretamente, considerava dura, mesmo sem saber o que João achava daquilo tudo - não estava contemplada pelo questionário. Eu sabia que, provavelmente, nada mudaria na vida de João. Mesmo assim, no íntimo, nutria alguma esperança de que, se João não engrossasse as estatísticas de ocupados e as taxas de desemprego subissem, talvez alguma política pública fosse feita para melhorar a vida das pessoas.

Como na primeira oportunidade em que deparei com um recém-demitido percebi que a voz da experiência estava certa e nada se podia fazer, quando folheei o questionário de João, já que não havia qualquer outro erro, apenas aprovei. Fiquei, porém, refletindo sobre o caso e várias questões pareciam ser postas pelo caso de João. Uma delas diz respeito ao problema da agência. Afinal, quem (ou o quê) fez aquele ocupado? Tornando mais geral a questão, João parecia perguntar o que age para conformar o mundo?

Este trabalho objetiva, portanto, apresentar o cotidiano da PED-RMPA, a fim de discutir essa questão. ${ }^{6}$ Muitas outras discussões interessantes poderiam

6 Há pelo menos duas outras questões que atravessam essa discussão, a saber, a referência e a autoria. É possível dizer que o empirismo supõe uma agência tremenda das coisas, que se imporiam e imprimiriam suas feições nas representações. Não é o que se vê no caso de João. Já a autoria passa a ser importante porque agência tem a ver não apenas com intencionalidade, mas também com quem faz as coisas acontecerem ou, nas palavras de Ortner (2007: 58), além da perseguição de projetos, agência é também poder ou atuação em relações de poder. Há, contudo, uma grande diferença entre a abordagem aqui seguida e a sugerida por Ortner, principalmente porque a antropóloga estadunidense somente considera a agência de humanos. 
surgir da análise da PED, mas optei por salientar esse debate, porque o dia a dia da pesquisa parece permitir pensar com importantes reflexões sobre agência, seja para ratificar concepções, seja para retificá-las. À primeira vista, foram o questionário e sua questão 17 que fizeram de João um ocupado, o que poderia ser lido na chave da agência dos não humanos, mote da chamada virada ontológica (Henare, Holbraad e Wastell 2007). Essa conclusão, contudo, ignora boa parte da riqueza do processo envolvido na PED-RMPA. Cada elemento da base de dados da pesquisa inclui um batalhão de coisas e suas ações. Para parafrasear Ingold (2012: 29), observar o mercado de trabalho com a PED "[...] não é ser trancado do lado de fora, mas ser convidado para a reunião".

Este artigo, então, localiza-se no âmbito da antropologia da ciência (Latour 2001). Assim sendo, não deixa de envolver certo esforço de simetrização. Em larga medida, Latour (1994) foi responsável pela difusão da ideia de uma antropologia simétrica, uma antropologia que, voltando dos trópicos, não se interessasse apenas por questões "marginais" e sim pelos centros de tomada de decisão. Mas o ponto mais importante da crítica latouriana talvez seja a noção de que tudo pode ser antropologizado (Giumbelli 2002: 104). Uma pesquisa que coloca cientistas sociais não apenas nas citações e nas referências bibliográficas, mas também como pesquisados é um esforço nesse sentido.

Este texto, por outro lado, não deixa de ser uma experiência de autoantropologia. Pois eu sou um desses cientistas sociais que se tornaram "nativos" nessa experiência de pesquisa. Strathern (1987) apontou os limites da antropologia que se debruça sobre a sociedade de que é fruto. Segundo a autora, dificilmente uma antropologia realizada por um antropólogo não ocidental em sua terra natal será um autoconhecimento, pois os conceitos que fundam a reflexão antropológica são alheios ao modo como aquele grupo pensa (Strathern 1987: 29-30). No presente caso, no entanto, trata-se de pesquisar com economistas, sociólogos e outros pesquisadores acostumados a acionar conceitos como sociedade e cultura em suas análises. Por outro lado, sou um antropólogo formado para desconfiar desses conceitos. Por isso, não deixa de ser importante pensar sobre em que medida há uma continuidade entre o conhecimento que produzirei e o modo como vivemos o dia a dia da PED-RMPA.

Para investigar esse dia a dia, tentei exercer uma etnografia das práticas científicas (Latour e Woolgar 1997). As técnicas de pesquisa utilizadas foram observação participante e conversas informais com registro em diário de campo. ${ }^{7}$ Realizei a leitura dos manuais da listagem, do entrevistador, da supervisão,

7 Meus apontamentos talvez não possam ser considerados propriamente um diário de campo em seu sentido clássico. Ainda que os apontamentos se formataram como um diário, registrando o dia em que os fatos aconteceram, não foram sistemáticos ou exaustivos. Apontei apenas os elementos que pareciam pertinentes para a discussão que estava pretendendo fazer. 
da crítica e da checagem. No final do processo de pesquisa, enviei por e-mail roteiros de entrevista com questões abertas para colegas de vários setores. ${ }^{8}$ No que se refere à observação participante, talvez no meu caso seja participação observante, ainda que por um motivo diverso de Wacquant (2002), pois atuar nesta pesquisa é minha obrigação como trabalhador. No período em que fiz o artigo, meu trabalho virou também minha etnografia.

Nessa etnografia, tentei seguir a trajetória de construção dos dados (por mais paradoxal que isso possa parecer). Desde a listagem dos domicílios dos setores censitários até a divulgação da taxa de desemprego e outras estatísticas do mercado de trabalho, passando pelos caminhos dos questionários. Dessa forma, as próximas páginas são a apresentação de pelo menos parte da biografia dos dados estatísticos, pois, parafraseando outro grande antropólogo, os dados, "[...] como as pessoas, têm uma vida social" (Appadurai 2008). Vamos então acompanhar essa história.

\section{E EU, O QUE FAÇO COM ESSES NÚMEROS? \\ DA LISTAGEM À SUPERVISÃO}

A entrevistadora apenas foi até a casa de João saber de sua história porque antes o setor censitário em que se encontra seu domicílio foi escolhido, assim como outros 166 setores, para participar da pesquisa naquele mês de maio. ${ }^{9}$ O passo seguinte foi a listagem, isto é, conferência do levantamento, feito pelo IBGE, de todos os domicílios dos setores sorteados. Verificado esse cadastro, entram em cena os estatísticos que formam a amostra probabilística a ser investigada em dado mês. Na RMPA, essa amostra conta com 7500 domicílios, investigados trimestralmente. Assim, a cada mês, bate-se na porta de 2500 residências. ${ }^{10}$

O Manual da Listagem é claro: "Se um domicílio não for listado, a chance de ser selecionado será zero, introduzindo, portanto, erros na amostra" (Seade 2005: 1). Por isso, é necessária muita "precisão", como diz o mesmo manual,

8 Optamos pelo e-mail por ser mais prático para todos. Minha ideia inicial era ter conversas privadas como cada um deles, mas dificilmente encontraríamos tempo para isso. Os entrevistados preferiram a flexibilidade do e-mail e isso também me poupou do trabalho de transcrição.

9 Setor censitário é "[...] uma unidade territorial delimitada, segundo a divisão de setores do IBGE" (Seade 2005: 2) Essa partição é feita pelo Instituto Brasileiro de Geografia e Estatística (IBGE) em cada Censo Demográfico para fins de pesquisa. Cada setor tem cerca de 300 domicílios. A PED-RMPA utiliza uma malha constituída por três painéis com 167 setores. Em um mês, pesquisa nos 167 setores do painel A. No mês seguinte, nos setores do painel B. No terceiro mês, investiga-se o painel C. Em seguida, retorna-se para o A, e assim sucessivamente. Quando todos os domicílios de algum setor já foram pesquisados, lista-se, para substituí-lo, outro setor com características socioeconômicas parecidas.

10 Ainda que a amostra seja completada apenas trimestralmente, a PED é uma pesquisa mensal, pois os dados são agregados para se produzir informações sobre o mês. Como se pesquisam domicílios, a PED também é dita "domiciliar". 
no processo de listagem. Isso porque está em jogo a eficácia da magia da amostra, pois esta é uma parte que pode falar do todo. É como se a amostra - os 7500 domicílios - encompassasse o todo - todas as casas da RMPA.

Ainda que eu possa ser defenestrado pelos meus amigos estatísticos ao fazer essa comparação, a galinha zande descrita por Evans-Pritchard (2005) parece ter muito a dizer sobre a amostragem. Assim como o oráculo de veneno, a amostragem exige a construção de um sistema cujo resultado não se pode controlar para que a verdade emerja. Daí a importância da aleatoriedade. Ninguém quis que a casa de João fosse selecionada, apenas o acaso.

Os responsáveis por comandar a amostragem são os estatísticos. Para agradá-los, eu poderia dizer que eles são como os príncipes azande, que dirigiam os oráculos mais acreditados. Se é possível dizer isso, é também verdade que os estatísticos são nobres modestos. Não se cansam de repetir: "Numa pesquisa por amostragem, nunca teremos certeza sobre como o universo de pesquisa se comporta". Mas isso não impede que na última quarta-feira de cada mês se divulgue que a taxa de desemprego na região metropolitana ficou em tantos por cento, que subiu ou baixou em relação ao mês passado. Também não impossibilita o governo de gestar políticas públicas a partir de pesquisas como a PED.

Quando já estiverem descobertos os domicílios que têm a capacidade de relevar como anda o mercado de trabalho, entra em ação a coordenadora de campo. Ela distribui os setores entre os 18 entrevistadores, que são terceirizados. Alguns critérios são levados em conta neste momento. Há entrevistadores que preferem a "classe popular". Outros se especializaram na "classe alta".

Definido quem irá até cada setor, está na hora de encaminhar cartas para os moradores. A intenção é convencê-los da importância de participar do nosso oráculo e salientar que a identidade de todos os entrevistados será preservada. Novamente aparece a classificação dos setores segundo a classe imaginada de seus moradores. Bairros de classes média e média alta recebem cartas com informações mais aprofundadas, pois as taxas de "recusas" são aí maiores. Inclusive se envia fotografia do entrevistador, seu nome completo e parte do número de seu documento pessoal.

Todas essas ações são feitas antes de o mês da pesquisa começar. Quando o mês inicia, a primeira atividade a ser realizada é a "largada". Consiste em uma reunião com os entrevistadores, que às vezes inclui a transmissão de recomendações. O objetivo principal, contudo, é a indicação dos setores que serão investigados no primeiro período. $\mathrm{O}$ mês de pesquisa é dividido em três períodos, encerrados por dois dias de "agenda", em que os entrevistadores peregrinam até as salas dos supervisores, entregam-lhes os questionários preenchidos e recebem outros setores para pesquisar.

Munidos com "capas" e "blocos F", as partes, respectivamente, domiciliar e individual do questionário, bem como com cópias das listagens e dos mapas, para poderem se localizar nos setores, os entrevistadores vão a campo. 
Conforme o Manual do Entrevistador (Seade 2010), eles devem fazê-lo apenas nos dias do mês-calendário, mesmo que, se a entrevista ocorrer nos primeiros dias do mês, várias perguntas possam se referir a dias do mês anterior. E precisam aplicar os questionários pessoalmente. ${ }^{11}$ São exigidas três idas a cada domicílio, em turnos e dias da semana diversos, a fim de encontrar mais pessoas em casa. "Não adianta ir à Restinga às três da tarde de uma segunda-feira. Não vai encontrar ninguém!", é uma expressão comum de se ouvir pelos corredores. ${ }^{12}$ Apenas pessoas com dez anos ou mais - que formam a população em idade ativa (PIA) - podem ser entrevistadas, ainda que sobre as menores de dez se registre dados pessoais, como sexo, cor, frequência escolar, etc. Somente maiores de idade podem dar informações sobre outros membros da família. Não se pergunta a empregados ou a vizinhos. O entrevistado não pode ter contato direto com o questionário. São várias as interdições, outro ponto em que se aproximam a PED e o oráculo de veneno, ainda que neste último caso os interditos sejam sexuais e alimentares (Evans-Pritchard 2005: 147). ${ }^{13}$

Também como um zande, um entrevistador pode esconder que infringiu alguma interdição. É possível falar com algum vizinho para saber a que horas pode encontrar alguém em casa. Ou falar com um empregado da casa e conseguir o telefone do morador.

Já a aplicação do questionário propriamente dita adquire certo ar cerimonial. Há, por exemplo, um texto que deve ser dito pelo entrevistador ao se apresentar. Seguir a ordem das perguntas é também uma obrigação. Se a aplicação é uma cerimônia, trata-se, em grande medida, de uma cerimônia de trocas de dádivas. A vida dos moradores pode ser convertida em uma informação, que, por sua vez, pode ser uma dádiva - a informação é dada. O manual é explícito ao afirmar a necessidade de evitar que se crie, nos entrevistados, expectativa com relação ao recebimento de benefícios:

“[...] evitar por todos os modos criar uma situação de expectativa (lembre-se de que, se trata de uma pesquisa de emprego/desemprego) quanto à obtenção de qualquer beneficio, associado à realização da pesquisa" (Seade 2010: 2).

Mas o entrevistador, para ser atendido, apela para o caráter altruísta da pesquisa - o quanto as informações podem auxiliar o desenvolvimento científico e

11 Já houve casos de entrevistadores que "terceirizaram" a aplicação dos questionários, foram descobertos e, em razão disso, perderam o emprego. O motivo para esse repasse de trabalho não ficou claro para mim. O fato é que os entrevistadores podem ser empregados terceirizados, mas eles não podem terceirizar o seu serviço.

12 Restinga trata-se de um bairro de classe popular de Porto Alegre.

13 Há também interdições ao preencher o questionário. Utiliza-se apenas grafite - o uso de canetas é proibido, salvo exceções, as quais ainda observaremos mais de perto. 
a gestão de políticas públicas, ou seja, aspectos geralmente vinculados ao bem coletivo. É preciso agradecer no final. Além disso, tem-se o dever de expressar "[...] uma atitude cortês e conciliadora" mesmo diante de uma "recusa", situação em que um entrevistado nega converter sua vida em informações e, por conseguinte, em um dom. ${ }^{14}$

O caráter cerimonial da vida do questionário, contudo, mescla-se com suor, poeira, bebidas que neles se derramam. A prática das entrevistas exige muito mais do que cerimônia. Os entrevistadores mais antigos são ditos "tarimbeiros" ou "que tem cancha", porque conhecem os atalhos dos questionários. "O entrevistado nem sente e o Evaldo já está com o questionário preenchido", disse, em um evento público, uma das coordenadoras nacionais do Sistema PED sobre a astúcia de um entrevistador gaúcho. Os questionários da PED, como boa parte das outras coisas, circulam e passam pelo cerimonial próprio dos manuais e pela dinâmica da prática, que exige improvisos.

Essas circulações dos questionários são apenas parte, ainda que significativa, dos caminhos dos dados estatísticos. Se esses dados são dádivas que os entrevistadores recebem, logo eles são convertidos em dinheiro. Pois a remuneração dos entrevistadores é composta por dois elementos, um fixo e um variável. Este último é diretamente proporcional ao número de questionários que eles entregam "realizados" em um mês.

Por isso, assume grande importância a "condição da entrevista", um campo do questionário que remete, ao mesmo tempo, a uma situação domiciliar. Uma entrevista pode ser "realizada", uma "recusa", "incompleta", um "domicílio fechado", um "domicílio vago" ou uma "UI" ou "unidade inexistente". Para um entrevistador, interessa entregar o máximo possível de questionários realizados (e encontrar, em alguns casos, várias UI, como veremos adiante). Isso porque somente os dados dos questionários nessa "condição de entrevista" podem ser convertidos em mais salário. Está-se diante, então, de mais um campo etnográfico em que é bastante pertinente a sugestão de tomar dádiva e mercadoria não como tipos de coisas e sim como situações da biografia das coisas, abordagem ligada a Appadurai (2008).

Tanto é que um questionário "incompleto" não incrementa um tostão na renda do entrevistador. Grosso modo, incompleto é o questionário que apresenta informações apenas de alguns dos moradores do domicílio. Ou seja, a dádiva não foi plena. Nem todos os indivíduos quiseram colaborar com a pesquisa. Assim, chega-se a uma equação no mínimo singular, pois, na política de valor da PED, a dádiva mais plena é que pode ser convertida em dinheiro. Isso

14 Há relatos de recusas bastante impactantes. As mais comuns remetem a críticas ao governo, já que instituições públicas executam a pesquisa. Um relato que me marcou bastante foi o de uma entrevistada que, não satisfeita em negar as informações, tomou a bolsa da entrevistadora e rasgou os questionários que ela carregava, muitos deles já preenchidos. 
contrasta com outras políticas de valor brasileiras, que estabelecem rotas justamente para preservar as dádivas mais plenas da monetarização. ${ }^{15}$

Qualquer que seja a "condição da entrevista", o questionário volta do campo para a mesa do supervisor. Cada um dos seis supervisores atende três ou quatro entrevistadores. A rotina do trabalho de supervisão possui dois eixos, como a supervisora Luísa explicou. O primeiro diz respeito ao controle do campo. "Receber material dos entrevistadores (entrevistas), [...] atualizar o sistema [de informática], aprender novo sistema”, enumerou Luísa. Esse eixo do cotidiano da supervisão remete à ideia de que os entrevistadores e especialmente seus questionários são um tanto ariscos, o que torna necessário mantê-los sob controle. Há inclusive um sistema computacional chamado vulgarmente de "Controle", que é alimentado, em parte, pelos supervisores e que permite acompanhar a trajetória dos questionários. ${ }^{16}$

Nesse momento da vida do questionário, é feita a contagem dos domicílios em cada "condição de entrevista" e entra em evidência o aproveitamento. "Cabe ao supervisor de campo a responsabilidade de atingir o maior aproveitamento possível da amostra que lhe foi destinada" (Seade 2006: 7). Assim, domicílios fechados, em que não se encontrou pessoas para responder ao questionário, domicílios vagos, onde sequer há pessoas morando, e entrevistas recusadas afetam o supervisor e ele pode ser cobrado por isso. O manual tenta, portanto, estabelecer outro encopassamento, agora entre supervisor e supervisionado. No mais das vezes, os supervisores negam a autoria e transferem a responsabilidade para os entrevistadores.

Também nesse momento ganham destaque os domicílios complementares. Trata-se de um tipo singular de domicílio realizado, tão especial que nos relatórios do programa "Controle" eles aparecem em uma rubrica particular. ${ }^{17}$ Esses domicílios surgem porque entre a listagem e a aplicação do questionário pode haver um intervalo significativo, que às vezes pode chegar a anos. Nessa intermitência, "a dinâmica urbana prossegue”, como ouvi ainda quando estava sendo treinado. Então, outras casas podem ser construídas, o que é mais comum em bairros populares. Um entrevistador gosta muito de "fazer um complementar", porque de um domicílio que lhe foi designado ele entrega dois questionários realizados. Como se verá adiante, esses domicílios afetam de forma muito significativa a equipe de checagem.

15 Os fluidos humanos, por exemplo, são objetos de várias regras que impedem sua comercialização no Brasil. Os doadores de sangue não podem receber uma contrapartida em dinheiro pela bolsa de sangue que doaram. O mesmo acontece com o sêmen doado para reprodução assistida e com a própria equação entre maternidade e dinheiro (Allebrandt 2014).

16 Essa tentativa de controlar os entrevistadores e os questionários não se restringe ao trabalho da supervisão e será um elemento importante da argumentação do próximo tópico.

17 A singularidade é tanta que recebem inscrições em caneta de tinta vermelha, a despeito da regra geral de se usar apenas grafite. 
O primeiro reflexo dessa afetação recai sobre o outro eixo da atividade da supervisão, eixo esse que remete às informações propriamente ditas. Consiste em "orientar [entrevistador] sobre metodologia e forma de trabalho, responder dúvidas, corrigir material, responder críticas”, como se expressou Luísa. Essa revisão de questionário por questionário primeiro deve ocorrer em setores com complementares, que precisam ser liberados o quanto antes para seguirem os próximos passos do fluxo do trabalho na PED.

\section{ANDO JÁ PELAS TABELAS: DA CRÍTICA AO DEPÓSITO (E ALÉM)}

Uma vez liberados pela supervisão, os questionários chegam à sala da equipe de "crítica". Como já dito, essa equipe é responsável pela avaliação metodológica de cada questionário. Folhamos questionários para verificar se os conceitos da pesquisa foram bem aplicados pelo entrevistador e se não há problemas no preenchimento, no enquadramento da situação ocupacional ou incoerência entre questões, aprofundando a avaliação já feita pelo supervisor. Porém, em razão das primeiras mudanças para a informatização dos questionários, processo que está em vias de acontecer, a equipe passou a acumular algumas atividades de protocolo. Em consequência disso, ganhamos a companhia de estagiárias, que, entre outras tarefas, recebem os questionários e classificam os "realizados" e os "incompletos" em ponta, meio ou prioridade.

Quando há prioridade, os membros da crítica ficam particularmente apressados. "Prioridade" são os questionários de setores censitários com um ou mais domicílios complementares. Devem ser analisados com premência, pois em breve virá alguma colega da equipe de checagem e a primeira pergunta que elas fazem é: “Tem complementar?”. Isso porque todos os domicílios complementares devem obrigatoriamente ser checados antes da expedição da folha de pagamento dos entrevistadores. Por isso, afetam a todos que trabalham na pesquisa de campo da PED-RMPA.

A urgência se tornou inclusive motivo de piada entre nós: "Se tem prioridade, a gente nem almoça!” Essa frase foi dita pela crítica Bárbara em uma reunião com a coordenação da pesquisa. No momento, os coordenadores não tinham como avaliar se se tratava de uma hipérbole ou não. Desde então, a expressão tem efeito cômico na nossa sala. Mesmo assim denota a preocupação que a pilha das prioridades gera em nós. Perguntei aos meus colegas sobre isso. Bárbara e Carolina disseram desgostar do acúmulo de trabalho nessa pilha. Carolina inclusive confessou: "Me sinto um pouco culpada [quando a pilha de complementares está grande] e um pouco de saco cheio." São algumas folhas de papel, mas fazem toda a diferença.

O pessoal da crítica, contudo, não folheia apenas setores com domicílios complementares. Mesmo que com menor urgência, também os setores classificados como meio e ponta são revisados. Nesse processo de revisão, ocorre 
uma espécie de ritualização da entrevista. O questionário parece estar disposto para passar essa impressão. Ele está organizado em cinco blocos, cada um com certos objetivos. O bloco A é de identificação do domicílio, apresentando o endereço que foi listado. No bloco B, arrolam-se os moradores do domicílio, sendo que o total de famílias e de moradores, bem como a distribuição desses em grupos de sexo e idade, é informado no bloco C. O bloco D é chamado de bloco-controle e remete novamente à necessidade de controle. O bloco $\mathrm{E}$ caracteriza cada indivíduo no que diz respeito ao sexo, à idade, à cor, aos deslocamentos migratórios e à escolaridade. Por fim, o bloco F, destinado apenas à população em idade ativa (PIA), que inclui as pessoas com dez anos ou mais, aborda como cada indivíduo se insere (ou não) no mercado de trabalho.

Conversando com meus colegas da crítica, ficou claro que nossa atividade é algo como o inverso da atividade de preencher o questionário. No momento em que alguém é entrevistado, o pesquisador de campo e o questionário atuam de tal forma que transformam o relato do entrevistado sobre sua inserção no mercado em um "fluxo" do bloco F. Cada tipo de inserção - ocupado, ocupado com procura de trabalho, inativo, inativo com trabalho excepcional, desempregado, desempregado oculto pelo desalento e desempregado com trabalho precário - faz um caminho no bloco $\mathrm{F}$, definido pelas respostas dadas às primeiras perguntas, por isso ditas "classificatórias". ${ }^{18}$ A vida é tornada um fluxo e isso implica em muito resumo.

Já a atividade do crítico é reconstituir, a partir das pistas que o questionário nos oferece, a vida da pessoa. Nossa questão é: Será que a vida de João está adequadamente contemplada pelo questionário e de acordo com a metodologia da PED? Isso implica em muita imaginação e conjectura. "Acho interessante que conforme vamos fazendo a leitura do questionário, as respostas (alternativas marcadas, anotações, descrições, códigos e até 'rastros' de coisas que foram apagadas) vão nos ajudando a construir uma história possível do indivíduo entrevistado. Muitas vezes esse é um trabalho de quebra-cabeça que, quando o fluxo é mais complicado, quando há incoerência entre questões, ou especialmente quando as descrições/anotações não são muito esclarecedoras, exige um esforço de imaginação e pesquisa (no Google, com os colegas, no manual) para especular qual pode ser a situação real que o entrevistador tentou captar", disse Carolina. No mesmo sentido, Bárbara escreveu: "Observo o questionário verificando o preenchimento, a correta aplicação da metodologia. Imagino as pessoas, a relação entre elas, a coerência entre as posições no domicílio e na família, as idades, a cor, se o fluxo da condição do indivíduo (bloco F) seguiu a metodologia, sempre pensando no conjunto de pessoas que moram no domicílio."

18 Como o caso de João - abordado no início do artigo - deixa claro, vida do entrevistado pode ser uma coisa e o caminho no questionário outra. Há ainda que considerar a possibilidade de o entrevistado mentir. 
Se o crítico considera que está tudo adequado, ratifica o resumo feito em conjunto pelo entrevistado, pelo entrevistador e pelo questionário. O entrevistado, então, volta a ser um fluxo. Caso encontre alguma pendência - uma incoerência, um erro de fluxo ou lhe falte alguma informação para entender o caso -, redige uma "crítica", apresentando o que lhe impede de aprovar o questionário. A crítica é afixada no questionário, o que provoca mudanças em sua rota.

Antes, contudo, todos os questionários do setor, com ou sem crítica, ficam disponíveis para a equipe de checagem. Algum colega desse setor vem pela manhã e pela tarde até nossa sala para selecionar quais os questionários que serão checados. Conforme me explicou Nina, que trabalha na checagem, são verificados, mensalmente, cerca de 800 domicílios, entre os quais devem constar algumas prioridades, a saber, em ordem de importância, domicílios complementares, unidades inexistentes (UI), ocorrências de listagens, solicitação de checagem de algum setor ou entrevistador em especial. Ocorrências de listagens são afixadas pelo entrevistador ou por seu supervisor aos domicílios a que elas dizem respeito e remetem a divergências entre as listagens e a realidade fora do escritório. Em geral, trata-se de novas residências que cobrem terrenos antes sem construções. De novo, está-se diante de um papelzinho que faz toda a diferença.

Nesse sentido, mais interessante ainda é o caso das unidades inexistentes. São domicílios que, como o próprio nome diz, não existem. Isso não os impede de provocarem o maior rebuliço, especialmente na equipe de checagem. Por efeito cascata, afetam a crítica. Também afetam os entrevistadores, porque o checador precisa avaliar se, de fato, o domicílio não existe e, nesse caso, busca saber quando foi destruído. Se envolve um erro da listagem, que teria, por exemplo, listado uma residência onde era um comércio e ninguém mora, é de praxe supor que o entrevistador foi prejudicado e deve receber como se tivesse feito o domicílio. No mais, porém, as UI são terrenos onde havia um domicílio, mas foi demolido.

Mas além de correr atrás de UI, o que um checador faz? Nina me disse que a atividade de seu setor tenta assegurar a "qualidade da pesquisa". Para isso, verifica-se se o endereço pesquisado realmente é o indicado na amostra (Seade 2008). Conforme o Manual da Checagem (Seade 2008), o checador ainda confere se o entrevistador abordou adequadamente o domicílio, se fez as perguntas de modo correto, se as informações realmente conferem. Enfim, procura garantir que a amostra foi pesquisada e segundo os preceitos que já elenquei no tópico anterior. Apenas assim a equipe de estatísticos se sente à vontade para fazer a mágica que permite a amostra falar sobre toda a RMPA.

Para tanto, os checadores também têm seus instrumentos. Cada domicílio checado recebe uma "folha de checagem de questionário" (FCQ), onde constam todos os itens que devem ser conferidos com os moradores do domicílio. Se 
tudo confere, em breve, os questionários voltarão para a nossa sala da crítica. Se, contudo, algo não estiver adequado, entra em cena outra folha poderosa, a "folha de esclarecimento de checagem", e se busca saber se o checador está certo - fazendo a "rechecagem". Se estiver, o entrevistador é ouvido, para que preste suas justificativas. Talvez seja preciso anular o questionário. Não se pode permitir que o entrevistador ponha em risco a mágica da estatística.

Se apenas alguns ajustes são suficientes para resolver a pendência, mais cedo ou mais tarde os questionários voltam para nosso setor. Às vezes, vêm ainda acompanhados por alguma FCQ ou mesmo com folha de esclarecimento de checagem.

O que mais nos agrada, porém, é que não somente questionários acabam chegando à nossa sala. Também bolos, salgados, refris e, principalmente, pessoas afáveis. A sala da crítica, já que é a maior sala em que se desenvolvem atividades referentes à PED-RMPA, tornou-se o lugar das confraternizações, principalmente para comemorar os aniversários dos colegas. No dia a dia, também se confraterniza, em geral, em torno das comidas e bebidas, como o chimarrão e o café. Muito além de apenas uma pesquisa, a PED-RMPA também é feita de muitas amizades.

Isso tudo em meio a monte de questionários. Retornados da checagem, os questionários se juntam com os que não foram selecionados para serem conferidos pelos checadores. Então, são divididos em dois grupos. Os que possuem crítica seguem para os supervisores, que tentam sanar as dúvidas dos críticos em conjunto com os entrevistadores.

Em geral, as críticas se referem a erros de codificação da ocupação do entrevistado e da atividade do negócio onde trabalha. Sabemos isso porque, nos últimos meses, temos trabalhado na construção de um banco de dados dos erros apontados pela equipe de crítica. As críticas são codificadas segundo uma tabela e, em seguida, os códigos são digitados. A ideia é conhecer as questões nas quais os entrevistadores têm maior incidência de erros. Planejamos utilizar as informações para futuras reciclagens dos entrevistadores.

Com relação às críticas, nós, os críticos, compartilhamos certa angústia. De fato, diante das alterações feitas em decorrência de alguma crítica que um de nós fez, não sabemos em que medida a mudança foi feita para adequar à realidade do entrevistado e o quanto a modificação apenas tentou resolver de vez a querela. Perguntei aos colegas se se sentiam receosos ao fazer críticas. Carolina inclusive desenvolveu uma estratégia para enfrentar essa dúvida: "O que às vezes faço na tentativa de minimizar esse risco [de ter modificações que não objetivam descrever melhor a situação do entrevistado] é escrever a crítica pedindo esclarecimento da situação, fazendo um monte de perguntas mas sem apontar o que teria que ser alterado no questionário para ele ser aprovável."

Bárbara relatou que já deixou de fazer crítica para evitar uma modificação apenas para que o questionário fosse aprovado. Ela se recorda que, ainda em 
2013, topou com um domicílio cujos indivíduos tinham cor amarela. Eram japoneses com nomes claramente orientais. Uma das moradoras, contudo, tinha nome de Luíze e era parente dos outros entrevistados por afinidade. Luíze era gaúcha e sua cor estava como branca. Diante da situação, Bárbara resolveu perguntar se Luíze tinha, efetivamente, cor diferente dos demais membros do domicílio. Luíze voltou amarela. E Bárbara ficou se perguntando se a entrevistada sempre fora amarela ou era branca, como boa parte dos seus conterrâneos, e apenas ficou amarela em razão da crítica.

Há, nesse ponto, uma questão de autoria. Segundo a metodologia da PED, um crítico não pode alterar nada. Se verifica um mau domínio da metodologia, um erro de preenchimento ou qualquer outro problema em um questionário, não utiliza a borracha. Toma uma "folha de crítica" e a preenche. É como se tentássemos nos isentar da forja do questionário. Desejamos que o questionário do João, sobre o qual escrevi no início do artigo, apenas fale sobre sua vida, sua família, sua situação. Queremos que nossa contribuição para a história de João ou para a cor de Luíze seja uma ausência.

Ausentar-se - tentar não fazer nada, não provocar nenhuma diferença - dá muito trabalho. Muitas vezes, ao preencher uma "folha de crítica", escrevemos várias palavras somente para que uma resposta seja transcrita para a "casela de digitação". Isso sem falar no trabalho que geramos para os colegas. As nossas estagiárias precisam encaminhar para supervisão o questionário com crítica tanto fisicamente quanto no sistema Controle. Os supervisores têm suas mesas lotadas pelos questionários com crítica. Os entrevistadores se queixam das numerosas críticas. Parece que cada tentativa de sair do mundo gera um repuxo, que nos engole e nos engaja ainda mais.

Já os que não têm crítica ou os questionários cujas críticas já foram resolvidas seguem para a digitação. A digitação é um momento crucial para que as histórias de João e de outros moradores da RMPA possam ser vistas em tabelas e gráficos de estatísticas. Torna as inserções no mercado de trabalho carregáveis, tal como a referência circulante descrita por Latour (2001). É possível enviar por e-mail, salvar em pen-drives, colocar em artigos. Para isso, são fundamentais nossas estagiárias. Depois de ter feito todo o serviço de protocolo, garantindo o controle sobre cada movimento dos questionários, elas digitam seus conteúdos propriamente ditos - as informações do domicílio, as informações individuais e os fluxos dos blocos F.

No momento da digitação, são formados "lotes", conjuntos de aproximadamente 20 questionários que não necessariamente compartilham características comuns. Esses lotes não deixam de ser mais uma política de controle sobre os questionários, pois os tornam rapidamente localizáveis. Talvez os questionários pensem em fugir do nosso controle, tomar caminhos que não aqueles predefinidos nos organogramas da PED, mas nós sempre temos uma carta na manga. 
Uma vez digitado, o lote segue para a "consistência eletrônica", que também é realizada pela equipe de crítica. A "consistência” faz uma série de cruzamentos entre as informações para verificar se ainda há algum conflito entre dados. Essa etapa é bastante importante para conferir se a digitadora não se enganou na hora de apertar os botões do teclado. Como esse é um trabalho repetitivo e intenso, são comuns erros nesse sentido. Há, por exemplo, o que chamamos de "deslocamento", digitar a resposta de uma questão nos espaços destinados à questão anterior ou seguinte, o que gera várias "mensagens de consistência". Também aparecem mensagens referentes a incoerências entre as informações que passaram despercebidas pela crítica. "A consistência é a hora de vestir as sandálias da humildade", costuma dizer o meu colega de crítica Nicanor.

Mais uma vez, emerge uma questão de autoria. Se o crítico se esforça, como vimos há pouco, para evadir e não interferir na construção do dado, o que implica numa trabalheira, a consistência deixa claro que essa ausência é também autora. Isto é, é responsável pelo dado, pois faz uma enorme diferença - pelo menos na vida do dado estatístico. Não é, então, à toa a aflição de um crítico diante de erros que ele próprio deixou passar. Perguntei aos meus colegas de crítica como eles se sentem frente a um relatório de consistência que apresenta erros em questionários que eles criticaram. "Por um lado me sinto muito mal por ter deixado passar [um erro no questionário] e por outro um pouco aliviada porque fui eu mesma, e não nenhum dos colegas, que encontrei minha própria rateada [ao fazer a consistência]", respondeu Carolina. Bárbara destacou que a consistência é um momento para rever sua atividade: "[Diante de um erro que deixei passar], penso que preciso ficar mais atenta".

Bárbara, por outro lado, lembra que a autoria é partilhada. "O questionário", comentou ela, "passa por vários olhares antes de ser digitado e ir para a consistência; neste caso, todos que analisaram e inclusive quem digitou, pode, em parte, ser responsável pelo equívoco". No bloco D, há espaços para o entrevistador, o supervisor, o crítico e o checador assinarem quando aprovam o questionário. Ao digitar, as estagiárias colocam seus números e ainda assinam o lote que digitam. A autoria pode facilmente ser rastreada, especialmente para destacar a produtividade de alguém ou para responsabilização por um erro.

Com todos esses erros corrigidos, as atividades do "Núcleo de Pesquisa de Campo" estão encerradas. É hora de mandar os questionários para o arquivo, onde ainda ficarão por três anos antes de serem incinerados. Os questionários que tanto provocaram aflições e mexeram com nossos cotidianos descansam no ostracismo dos depósitos.

Também é o momento de ligar para o quinto andar, onde fica a equipe de estatística e de análise socioeconômica. As análises só podem ser feitas se o banco de dados estiver perfeito. A supervisão, crítica, checagem e consistência formam o chamado "controle de qualidade" da PED. Fazemos por merecer: como vimos, estamos sempre de olho nos movimentos dos questionários e nos 
seus conteúdos. E torcemos para receber questionários com os fluxos mais tradicionais e sem erros. "[Eu gosto] Dos aposentados com renda boa ou razoável (de preferência aqueles que informaram a formação escolar/acadêmica). Porque é rápido de olhar, tem pouca coisa pro entrevistador errar, não faz com que eu me sinta mal pela situação da pessoa, e me dá alguma pista do trabalho que o indivíduo tinha quando ativo (curiosidade é brabo!)”, escreveu Carolina. Costumo dizer para meus colegas que, se Foucault percebeu processos de disciplina do corpo (Foucault 1987), os quais buscam corpos dóceis, podia ter apontado para docilidade das coisas. Na PED-RMPA, queremos questionários e informações dóceis. Nesse sentido, a "consistência eletrônica" deixa claro o governo sobre os questionários e as informações. Se há seis pessoas ou mais em uma família, gera-se uma mensagem de advertência no relatório de consistência. O mesmo acontece se uma remuneração é maior ou igual a 30.000 reais.

O que parece que não aprendemos, porém, é que, ao controlar as coisas, as coisas também nos controlam. Desejamos docilidade dos questionários, mas são eles que nos têm dóceis. Por oito horas diárias, os críticos, por exemplo, folheiam questionários. E esmerando a "qualidade da pesquisa", vigiamos os colegas. Nós, críticos, desgostamos quando pegamos questionários digitados de modo displicente. Mesmo com cuidado para não sermos indelicados, procuramos "cuidar" o trabalho das estagiárias que digitam. Em geral, vigiamos-lhes e tentamos evitar seus ócios. Caso contrário, os lotes a serem digitados se acumulam e elas digitam apressadamente, o que parece multiplicar os equívocos.

Mesmo com vários mecanismos de controle, as informações e os questionários teimam em burlar as regras. Algumas iniciativas nesse sentido são rapidamente tolhidas. O caso de João, mais do que explorado neste artigo, é um exemplo disso. Outro exemplo é a idade. Existem apenas duas caselas para a idade. Então, pessoas com 100 anos ou mais entram para a base de dados com apenas 99. Outras tentativas de burla são mais bem-sucedidas. Alguns questionários simplesmente somem. Há erros em questões que não são pegos pela consistência eletrônica. Se uma pessoa é branca, mas a estagiária digita que ela é negra, ninguém perceberá o equívoco, exceto algum crítico mais curioso que, por acaso, revise toda a digitação. E também os humanos burlam eficazmente as tentativas de docilização. Às vezes, paramos o trabalho para falar sobre nossas vidas particulares ou por atividades sindicais.

Além de sermos o controle de qualidade, desenvolvemos pelo menos um movimento paralelo. Já vimos que a digitação torna as inserções no mercado de trabalho carregáveis. Também já foi apontado que, não raro, questionários ficam empoeirados, sujos por bebidas, etc. Essa sujeira fica particularmente perceptível se forem comparados um questionário e uma tabela em uma divulgação. As próprias normas técnicas da apresentação de tabelas primam pela limpeza visual. Sugere-se que se use o menor número possível de linhas e colunas. Trata-se, pois, de uma espécie de higienização. Ao subir para o quinto 
andar, João não sua. É apenas uma combinação singular de números. A singularidade dessa coleção é bastante importante, como Latour (2001) salientou. Essa singularidade permite que não haja um salto entre coisa e palavra, mas várias traduções em cadeia que podem ir em direção à palavra ou retornar em direção à coisa. João vira um número, mas algum curioso pode ir até o depósito e ver seu questionário. Ou mais: pode verificar no banco de dados seu endereço e voltar a bater em sua porta.

Não por acaso, as informações ficam, aos poucos, mais rarefeitas conforme se passam as etapas do organograma da pesquisa. Perguntei para a supervisora Luísa se ela acaba sabendo mais detalhes da vida dos entrevistados. "Alcoolismo, drogas, região de tráfico e violência, problemas familiares dos entrevistados, dificuldades de entrevistar, etc.", elencou a colega. Ela também disse que escuta detalhes sobre a vida pessoal dos entrevistadores. "Entrevistadora que tem filho que foi morar com o pai agora que é adolescente, entrevistadora que tem marido com problemas com álcool e filho que não gosta de trabalhar, filha de entrevistadora que faz ginástica olímpica na Sogipa, etc.", enumerou Luísa. A essas informações, dificilmente um crítico tem acesso. ${ }^{19}$

Nesse processo de higienização, a equipe de crítica desempenha papel significativo. É o crítico que confere cada tradução. Uma senhora aposentada que faz crochê quando lhe sobra tempo se torna uma inativa com trabalho excepcional. Um jovem que desiste de procurar emprego porque os empregadores exigem experiência vira um desempregado oculto pelo desalento. Forma-se a população economicamente ativa (PEA) e assim por diante. Não adianta poder carregar uma realidade mal descrita, que mistura alhos com bugalhos. Seria o mesmo que tentar levar algo em um saco furado.

Chegando os dados no quinto andar, os estatísticos completam suas mágicas e fazem a amostra falar sobre o todo. Para isso, se utilizam de várias "fórmulas", como é de praxe para um mágico. ${ }^{20}$ Em seguida, entram em cena sociólogos e economistas acostumados em justificar os movimentos do mundo. Eles conseguem ver movimentos da economia e da sociedade na flutuação das taxas de desemprego, das remunerações médias, das listas de setores da economia que mais empregam e assim por diante. É o produto interno bruto (PIB) que cresce ou que deixa a desejar ou ainda outra variável tão ou mais importante que compõe cada informação que se vê em uma tabela ou em um gráfico.

19 Em certo sentido, a checagem é já um processo de retorno. Mas isso não impede que o sentido geral do processo de construção do dado seja em direção à facilitação do seu carregamento. Pelo contrário: a checagem apenas reforça que esse direcionamento é reversível, sendo possível circular.

20 Da mesma forma que a antropologia, em geral, insiste em não destituir de verdade as práticas de bruxaria Azande, tampouco cabe aqui avaliar a veracidade desses índices produzidos em pesquisas estatísticas. O que se deve destacar é sua eficácia no cotidiano de Estados, como o brasileiro, e de seus cidadãos. 
Divulgadas as conclusões das pesquisas, outras composições são percebidas por outros atores. É comum que secretários do governo do estado ou outros membros da administração pública que não se engajam como cientistas à PED-RMPA tomem suas taxas como se valessem para o estado do Rio Grande do Sul como um todo. Em prévia da campanha para reeleição à Assembleia gaúcha, o então secretário do Trabalho Luis Augusto Lara afirmou em maio de 2014: "[...] se tu qualificas, habilitas mais gente ao trabalho. Hoje o Rio Grande do Sul é o estado com menor índice de desemprego". ${ }^{21}$ À época, meus amigos estatísticos me ajudavam a perceber que a RMPA tinha a menor taxa de desemprego entre as regiões metropolitanas pesquisadas, mas nada me diziam sobre o Rio Grande do Sul.

\section{NOTAS FINAIS}

Neste texto, buscou-se seguir o dado estatístico, desde sua produção até sua divulgação. Tentou-se traçar, assim, uma biografia da taxa de desemprego produzida na PED-RMPA. Isso implicou em apresentar fragmentos do cotidiano de pesquisa. Percorrido esse caminho junto com questionários, entrevistados, colegas e uma porção de outras coisas, viu-se que há muito mais mundo em uma taxa. Quando se vê uma tabela, é possível enxergar não apenas números, mas também todo esse universo que acabei de descrever. Dádivas e monetarização, práticas de governo, rituais e suas cerimônias, vidas práticas e seu suor, enfim, um dado estatístico é um coletivo - esconde, dentro de si, todo um batalhão de coisas (Latour 2012).

Essas coisas têm agência? Vimos como um domicílio complementar mexe com a vida de todo mundo. Entrevistador recebe mais. Supervisor e crítico devem se apressar. Checagem precisa ser feita, e assim por diante. Em uma leitura apressada, não necessariamente errada (tampouco certa), poderia se dizer que se trata da agência do domicílio provocando diferença no mundo.

Mas o que é um domicílio complementar na PED? É o resultado de uma conjunção de outras coisas e suas ações. Envolve não ser considerado pelo listador, ser moradia de alguém, ter o domicílio do qual é complementar sorteado para participar da amostra, haver alguém em casa para ser entrevistado, ser supervisionado, criticado, checado, entre outras dezenas de coisas, que incluem, em geral, cimento, tijolo, etc. Algo parecido se poderia escrever sobre a ocorrência de listagem, a folha da crítica, a folha de esclarecimento de checagem. As coisas não se contentam em ficar fechadas em si mesmas. As coisas vivem umas nas

21 Jornal Folha do Sul, Bagé, 17 de maio de 2014: < http://www.jornalfolhadosul.com.br/notici a/2014/03/17/secretario-luis-augusto-lara-deixa-a-pasta-com-a-certeza-de-ter-concluido-desafio > (última consulta em maio de 2015, já não disponível). Atualmente, o IBGE produz um dado sobre o índice de desemprego estadual com dados da PNAD Contínua, o que ainda não acontecia. 
outras e se fazem mutuamente (Ingold 2011). Ninguém seria crítico se não houvesse questionários para avaliar. Um questionário não pode ser aprovado sem o aval de um crítico.

Não é à toa, então, que se enviam cartas para os moradores. A PED, como um todo, é um convite para uma reunião (Ingold 2012). O questionário é outro chamamento para participar do dado estatístico. O entrevistado conta sua história; o entrevistador a transforma em um fluxo. O bloco D e seus espaços para assinaturas são outros indícios dos incentivos à participação.

Talvez se pudesse ver aí certa proximidade com as ideias de agentes primários e secundários de Gell (1998). Por detrás de cada coisa que aparentemente age, há outras tantas que a compõem e que auxiliam em cada movimento, carregando parte dos fardos. Mas Gell pontua algo bastante distinto. Insiste na ideia de agência. E em certo antropocentrismo. Daí o sentido para a distinção entre agentes primários e secundários. Assevera o antropólogo que as coisas podem ser agentes, porque indiciam alguma ação. Mas apenas em um nível secundário. Pois os agentes primários são sempre humanos que possuem intencionalidade.

Ao contrário, considero que assumir uma postura simetrizante (Latour 1994) seja mais prudente e frutífero para entender o cotidiano da PED-RMPA. E tomar o mundo como um entrelaçar de coisas, que são constituídas pelos caminhos que descrevem e pelos povoamentos mútuos que estabelecem com outras coisas nessas trajetórias (Ingold 2011, 2012). Assim sendo, todas as coisas contribuiriam, em alguma medida, para o constante transformar do mundo. Até as unidades inexistentes, que, como o nome diz, não existem, fazem uma tremenda diferença. Ao mesmo tempo, aos poucos perceberíamos que as coisas se dissolvem em outras, a ponto de não se conseguir perceber quem é que está agindo. Uma UI, para seguir no exemplo, foi uma casa listada por um listador, sorteada por um estatístico, destruída por um morador, procurada por um entrevistador e assim por diante.

Se não é possível identificar um agente sem perceber que se trata, na realidade, de uma grande composição, quem atua e transforma o mundo? Quem faz gemer a terra? Talvez fosse correto sugerir que a terra se geme.

Dessa forma, a própria distinção entre agentes e pacientes é questionada. Os economistas classificam os humanos em população economicamente ativa (PEA) e inativos, conceitos centrais para a PED. Há também a ideia de população em idade ativa (PIA). Desconfio que os inativos sejam muito ativos! Provavelmente, há estudos sobre a importância, inclusive econômica, dos ditos inativos. Não é para menos: se mesmo a tentativa de se ausentar do crítico é um modo de autoria e deixa sua marca no mundo, do que não é capaz um aposentado e seu ordenado?

Ao fazer semelhante afirmação, então, distancio-me do senso comum dos economistas que fundamenta conceitos como PIA e PEA. Isso remete à outra 
questão, proposta por Strathern (1987), que orientou esta reflexão: em que medida há uma continuidade entre o conhecimento que produzi sobre a PED-RMPA neste artigo e o modo como vivemos o seu dia a dia? Ao escrever este texto, percebi que a antropologia permite fazer emergir elementos que estavam subreptícios. A pilha das prioridades afeta os críticos e nós sabemos disso. Mesmo assim, compartilhamos, pelo menos no nível discursivo, do estatuto dominante dos objetos no mundo euro-americano, estatuto este que não reconhece esses afetos. Portanto, parece haver uma continuidade entre os saberes "nativo" e antropológico. A contribuição do antropólogo para esse mundo de coisas são as aproximações que nem sempre agradam a todos (não sei quem desgostou mais da aproximação entre oráculo e a amostragem, se os Azande ou os estatísticos), mas que ajudam a pôr em evidência fenômenos encobertos.

\section{BIBLIOGRAFIA}

ALLEBRANDT, Debora, 2014, "Negociando semelhanças, produzindo identidades: Orientação religiosa e herança genética na escolha de doadores de gametas”, Ciencias Sociales y Religión/Ciências Sociais e Religião, 16 (21): 137-151.

APPADURAI, Arjun, 2008, "Introdução: mercadorias e a política de valor", in Arjun Appadurai (org.), A Vida Social das Coisas. Rio de Janeiro: Editora da Universidade Federal Fluminense, 15-88.

EVANS-PRITCHARD, Edward Evan, 2005, Bruxaria, Oráculos e Magia entre os Azande. Rio de Janeiro: Zahar.

FOUCAUlT, Michel, 1987, Vigiar e Punir: Nascimento da Prisão. Rio de Janeiro: Vozes.

GELL, Alfred, 1998, Art and Agency: An Anthropological Theory. Oxford: Clarendon.

GIUMBELLI, Emerson, 2002, “Para além do 'trabalho de campo': reflexões supostamente malinowskianas”, Revista Brasileira de Ciências Sociais, 17 (48): 91-107.

HENARE, Amiria, Martin HOLBRAAD, e Sari WATEll, 2007, "Introduction: thinking through things", in Amiria Henare, Martin Holbraad e Sari Wastell (orgs.), Thinking through Things: Theorising Artefacts Ethnographically. Londres e Nova Iorque: Routledge, $1-32$.

INGOLD, Tim, 2011 , Being Alive: Essays on Movement, Knowledge and Description. Londres e Nova Iorque: Routledge.

INGOLD, Tim, 2012, "Trazendo as coisas de volta à vida: emaranhados criativos num mundo de materiais", Horizontes Antropológicos, 18 (37): 25-44.

LATOUR, Bruno, 1994, Jamais Fomos Modernos: Ensaio de Antropologia Simétrica. Rio de Janeiro: Editora 34.

LATOUR, Bruno, 2001, A Esperança de Pandora. São Paulo: Edusc. 
LATOUR, Bruno, 2012, Reagregando o Social. Salvador e São Paulo: Edufba/Edusc.

LATOUR, Bruno, e Steve WOOlgAR, 1997, A Vida de Laboratório: A Produçao dos Fatos Científicos. Rio de Janeiro: Relume Dumará.

ORTNER, Sherry B., 2007, "Poder e projetos: reflexões sobre a agência", in Miriam Pillar Grossi, Cornelia Eckert e Peter Henry Fry (orgs.), Conferências e Práticas Antropológicas. Santa Catarina: Nova Letra, 45-80.

SEADE - FUNDAÇÃO SISTEMA ESTADUAL DE ANÁLISE DE DADOS, 2005, Manual de Listagem dos Setores Censitários. São Paulo: Seade \& Dieese.

SEADE - FUNDAÇÃO SISTEMA ESTADUAL DE ANÁLISE DE DADOS, 2006, Manual da Supervisão. São Paulo: Seade \& Dieese.

SEADE - FUNDAÇÃO SISTEMA ESTADUAL DE ANÁLISE DE DADOS, 2008, Manual da Checagem dos Domicílios. São Paulo: Seade \& Dieese.

SEADE - FUNDAÇÃO SISTEMA ESTADUAL DE ANÁLISE DE DADOS, 2010, Manual do Entrevistador. São Paulo: Seade \& Dieese.

STRATHERN, Marilyn, 1987, "The limits of auto-anthropology”, in Anthony Jackson (org.), Anthropology at Home. Londres e Nova Iorque: Tavistock Publications, 16-37.

WACQUANT, Loïc, 2002, De Corpo e Alma: Notas Etnográficas de Um Aprendiz de Boxe. Rio de Janeiro: Relume Dumará. 